\title{
GERMÁN ESPINOSA: TRANSGRESIÓN Y CONTINUIDAD EN LA TRADICIÓN LITERARIA COLOMBIANA
}

\author{
GERMÁN ESPINOSA: TRANSGRESSION AND CONTINUITY \\ IN THE COLOMBIAN LITERARY TRADITION
}

\section{ORLANDO ARAÚJO FONTALVO 1}

\section{RESUMEN}

Este artículo analiza algunas de las más significativas experiencias vividas por el autor caribeño Germán Espinosa durante su infancia, pues, como afirma el propio escritor, éstos son los años esenciales. Asimismo, reflexiona sobre la estructura, la dinámica y las particularidades propias de ese entramado de relaciones y disputas que podría ser llamado el campo literario colombiano e indaga por los móviles que postergaron de manera excepcional el debido reconocimiento y la valoración de su obra. Por último, profundiza en la interpretación de su propuesta en el marco de la tradición literaria colombiana.

Palabras clave: Tradición, campo, cosmopolitismo, proyecto estético.

\section{ABSTRACT}

This article analyzes some of Caribbean author Germán Espinosa's most significant experiences during his infancy, which, as he affirms, are the essential formative years. Likewise, this article reflects upon the structure, the dynamics and the particularities that characterize that fabric of relationships and disputes that we might call the Colombian literary field. Moreover, it explores the motives that brought about an unusual delay in the due recognition and appreciation of Germán Espinosa's work. Finally, it

${ }^{1}$ Candidato a Doctor en Literatura, Universidad de Antioquia. Magíster en Literatura Hispanoamericana, Instituto Caro y Cuervo. Profesor investigador de tiempo completo de la División de Humanidades y Ciencias Sociales de la Universidad del Norte (Barranquilla-Colombia), Coordinador del Grupo de Investigación Studia (Colciencias). E-mail: oaraujo@uninorte.edu.co 
offers a more in-depth interpretation of his proposal within the context of the Colombian literary tradition.

Keywords: Tradition, field, cosmopolitanism, aesthetic project.

Recibido: 23.09.10. Aceptado: 05.06.11.

\begin{abstract}
No creo que sea posible ubicarme en escuelas, ni siquiera en tendencias. Mis maestros han sido de todas las épocas. [...] Soy, en ese sentido, un escritor de síntesis, no de escuela ni de capilla...
\end{abstract}

G. E.

$\mathrm{E}$

L CASO DEL ESCRITOR cartagenero Germán Espinosa (1938-2007) se revela, sin lugar a dudas, como uno de los más interesantes en la historia de las letras nacionales. Espinosa, uno de los más significativos y prolíficos escritores colombianos del siglo XX, cultivó todos los géneros literarios, precisamente porque no creyó mucho en ellos. Novelas, cuentos, poemas, ensayos, biografías, crónicas, obras teatrales constituyen su inapreciable legado. No pocas veces confesó: "Prefiero que digan de mí que soy un poeta que narra" (Torres, 2007: 101). La calidad de su prosa, entre barroca y modernista, se debe, en buena medida, a la equilibrada dosis de poesía que supo imprimirle tanto a sus narraciones de largo aliento como a sus relatos más vertiginosos.

El presente artículo indaga, en primera instancia, por los móviles que postergaron de manera excepcional el debido reconocimiento y la valoración de su obra. En segundo lugar, profundiza en la interpretación de su propuesta en el marco de la tradición literaria colombiana. Para dar cumplimiento a tales propósitos, se impone un análisis preliminar de algunas de las más significativas experiencias vividas por el autor caribeño durante sus años de infancia, pues, como afirma el propio escritor, éstos son los años esenciales, "los adultos no somos sino la caricatura del niño. En el fondo, todo lo que somos lo fuimos ya desde niños" (Espinosa Torres, 2000: 27). Asimismo, será necesario reflexionar sobre la estructura, la dinámica y las particularidades propias de ese entramado de relaciones y disputas que podría ser llamado, con Bourdieu (1995), el campo literario colombiano. Sin embargo, es fácil prever que será imprescindible ir mucho más allá del sociólogo francés para lograr comprender la cabal naturaleza del problema que nos ocupa. 


\section{COSMOPOLITISMO CARIBE}

... Jamás he dejado de ser un hombre caribeño, lo cual en algunos sentidos quiere decir revestido de universalidad.

En sus primeros años, Germán Espinosa pasó largas temporadas en el caserón cartagenero de su abuela materna, desde cuya azotea divisaba el mar resplandeciente. La presencia del Mar Caribe sería a todas luces definitiva en la visión del universo que, con el paso del tiempo, habría de configurarse en su obra. "Cuando aún contaba sólo días de nacido -reconoce el escritor-, mi madre me sumergió en sus aguas, en una especie de bautismo, de investidura simbólica. Ello dejó en mí señal indeleble" (2003: 22). Una huella similar habría de imprimirle la música que, algunos años después, saturaría sus oídos, esto es, el porro, el tango, el bolero, la bossa nova, los corridos mexicanos y hasta la música sinfónica. Toda esa diversidad, toda esa riqueza, contribuyó, sin una vislumbre de duda, al reconocimiento de la propensión universalista que Espinosa le atribuye a la imago mundi caribeña. Imagen del mundo que, dicho sea de paso, le autoriza a beber como escritor de múltiples y lejanas fuentes, con la libertad y el desparpajo de quien no reconoce temas, ni espacios, ni tiempos que le sean vedados. "Contemplar el mundo desde el Caribe significa hacerlo con los horizontes abiertos, sin ese provincialismo de la antigua mirada andina. Digo "antigua", porque hoy, con los veloces medios de comunicación de que disponemos, en cualquier parte vivimos la aldea global" (Ortega, 2008: 8).

A los siete años de edad, de nuevo en la infancia, Espinosa fue llevado por sus padres a Corozal, en las antiguas sabanas de Bolívar, donde por primera vez tuvo contacto con un ambiente distinto al que se respiraba en las señoriales callejuelas de la ciudad heroica. El corralito de piedra y calicanto frente al mar, donde había transcurrido hasta entonces su vida, dio paso abruptamente a una casa de campo, grande pero rústica, con un patio colosal repleto de árboles y plantas ornamentales. La diferencia de fondo estaría, según cuenta el propio autor en sus memorias, en la mentalidad de la gente que habitaba la sabana.

... El campesino de aquellos tiempos era un ser pueril y testarudo. Conservador hasta el tuétano, apegado con tozudez a las tradiciones más anacrónicas, creyente en rezos de pianches, devoto de las ánimas benditas y sumiso a las prédicas de los curas, permanecía en el más cándido analfabetismo y se sometía con regocijo al paternalismo de los hacendados (Espinosa, 2003: 37). 
De manera paulatina, el gusto evidente de Espinosa por la ciudad lo empujaría primero a Cartagena y luego a Bogotá. En estas dos ciudades, ambas con una fuerte tradición colonial y letrada, se cifra en buena medida el pensamiento de Espinosa. "Añoraba yo a Cartagena -dice el autor-con una melancolía lacerante. Me hacía una falta copiosa la ciudad. [...] En el campo me siento atacado de vértigos, experimento una soledad irracional, me punza una especie de desamparo o de orfandad" (48).

En este sentido, su arribo a Bogotá a los 16 años no hizo otra cosa que consolidar en el joven escritor su convicción universalista. Bogotá, quién lo duda, fue la ciudad amada de Espinosa, su segunda patria chica, la urbe bondadosa, a la vez "traicionera y perversa" (78) que escogió para vivir y para escribir, la misma que le inspiró versos de amor irreflexivo y dicterios por su crueldad y su dureza. "Cuando yo llegué a Bogotá [...] -recuerda en una entrevista-, la visión que allí predominaba era recoleta, como la de quien observa el universo por el ojo de una cerradura" (Ortega, 2008: 8). A pesar de las adversidades que Bogotá habría de depararle, resulta irreprochable su importancia en la formación ideológica de Espinosa. Dicho de otro modo, la perspectiva bogotana de entonces constituyó una suerte de catalizador para la plena configuración de su propuesta de un Caribe abierto a todas las corrientes del pensamiento universal.

No debe pensarse que, para Espinosa, el hecho simple de provenir de la zona cultural caribeña fuera garantía axiomática de una visión de mundo cosmopolita. De hecho, tanto a orillas del mar como en la gélida altiplanicie reconoció el autor la coexistencia de mentes libres y de espíritus prejuiciosos. Se trata, más bien, de la lúcida constatación de las diferentes corrientes de la cultura universal que, a razón de incontables avatares, se dieron cita en la cuenca del Gran Caribe. La concepción de Espinosa encuentra sustento, de manera inequívoca, en el influjo de múltiples y complejos procesos de mestizaje, sincretismo e hibridación operados en este privilegiado espacio que algunos no han vacilado en calificar como el más grande "mixer cultural"2 del planeta.

[...] Diré que tal propensión -la del Caribe por y para el universo- cobró hace mucho la fuerza de un destino. El mismo que, como dije, fue placentera o dolorosa y sutilmente tramado, en otros tiempos, por el

${ }^{2}$ Así lo llama el investigador Francisco Avella Esquivel. Véase, por ejemplo, "Bases geo-históricas del Caribe Colombiano". En Respirando el Caribe: Memorias de la Cátedra del Caribe Colombiano. Volumen I. Ariel Castillo Mier (Compilador). Barranquilla, Observatorio del CaribeUniversidad del Atlántico, 2001. 
conspicuo cruzamiento de todas las razas del planeta: la dulce y aborigen cobriza, la meridional europea que llegó en las carabelas, la negra que arribó en las galeras y que acabó replegándose en ese cálido entorno, la judía que a partir de la Colonia irradió desde el foco libertario de Willemstad, la árabe que inmigró ansiosamente en los albores del siglo, la amarilla que nos acecha desde los restaurantes pintorreados por pabilos y farolitos, y la de todo el resto del globo terráqueo que se concentró en las naves piráticas y cuya hórrida presencia dejó violadas a centenares de mujeres que retoñaron rubias pelambres escandinavas, zarcos ojos sajones, maldicientes belfos eslavos, embrujadoras miradas gitanas [...] (Castillo Mier, 2001: 77).

En muchos sentidos, como puede apreciarse, el Caribe universal de Espinosa se conecta con las tesis del pensador mexicano José Vasconcelos respecto de una raza cósmica, síntesis providencial de todas las razas del planeta. Más aún: las trasciende en la medida en que comprende que la cuestión no es simplemente racial sino, sobre todo, cultural e ideológica. "La imago mundi caribeña -concluye el escritor colombiano- es universal y dinámica. El hombre culto del Caribe dirige su mirada hacia todas las culturas y sabe apropiarse, sin perder su identidad, de todo lo que de ellas necesita" (Ortega, 2008: 8).

\section{ESPINOSA Y EL DEVENIR DE LA TRADICIÓN}

Pensé que la literatura colombiana merecía ser redimida de aquellos atolladeros abruptos, para que volara por los libres espacios de la imaginación.

G. E.

La noción de tradición, insoslayable si se quiere comprender la dinámica de la producción literaria, será entendida, en el marco del presente trabajo, como un complejo de relaciones que garantiza la continuidad histórica de la literatura. Es la tradición, justamente, la que posibilita el vínculo entre los distintos eslabones de la historia literaria. En términos más generales, la tradición es "todo lo que una generación dada asume de las anteriores, y lo que ha sido reconocido en determinado medio como digno de asunción" (Lissa, 1986: 222). En este sentido, habría que señalar que cada generación, incluso, cada agente, actualiza la herencia que recibe o que asume, haciendo de la tradición un fenómeno cultural que crece, cambia y se expande de manera incesante. Este concepto, sumamente útil en el campo de la historia 
y de la historiografía literaria, opera en dos ejes: uno temporal y otro espacial. El primero, eminentemente diacrónico, otorga a la historia literaria su carácter continuo; el segundo, en cambio, desde una perspectiva territorial, le imprime a las tradiciones de distintos países su auténtico carácter nacional. La investigadora polaca Zofia Lissa, en un valioso intento por elaborar una teoría de la tradición desde el campo musical, afirma que, más que cualquier otra cosa, la tradición es

Una red de variados residuos del pasado, espesamente tejida tanto en su estratificación temporal como en el sistema cualitativo, de muy diversa génesis, y que renueva con cada generación. Cada época histórica reinterpreta para su propio uso los elementos hallados a su llegada, para transformarlos y, sobre la base de ellos, hacer su aporte a la totalidad del arte dado, aporte que, a su vez, devendrá él mismo una tradición para los tiempos futuros, al constituir una aleación de elementos heterogéneos y sufrir una ulterior reinterpretación (225).

Un creador, en cualquiera de los campos de producción cultural, puede asumir $-y$ esto debe subrayarse- diferentes actitudes frente a la tradición: puede, por ejemplo, acatarla, puede modificarla o puede simplemente rechazarla, lo cual es paradójicamente una de las formas más activas de conectarse con la tradición. Ahora bien, para comprender la actitud de Germán Espinosa frente a la tradición literaria colombiana, es necesario, además de precisar las características dominantes de dicha tradición, volver sobre ciertas disposiciones adquiridas por el escritor durante la infancia y que, de una forma o de otra, condicionaron su posterior quehacer literario y sus más significativos procesos de selección.

En este orden de ideas, uno de los acontecimientos de mayor relieve ocurre hacia los diez años de edad, cuando Espinosa tiene acceso tanto a la biblioteca de su padre como a la de su abuelo. En ambas sobresalían en número las obras literarias de otras latitudes, principalmente europeas. Obras que, por lo demás, no podían conseguirse en las librerías colombianas de la época. Una exquisita gama de estilos, de géneros y de autores extranjeros vino a reforzar la vocación universalista de Espinosa, surgida, como se ha señalado en extenso, de las entrañas del Caribe en tanto espacio histórico e ideológico de hibridación cultural. "Creo que la mayor influencia es la que queda de mis lecturas de infancia, especialmente las novelas románticas francesas, en especial Víctor Hugo, Dumas, Stendhal, Balzac y Anatole France" (2000: 14). Todo ello ayuda a comprender el rechazo del escritor hacia toda aquella tradición que rezumara costumbrismo, regionalismo o simple color local. "En la medida en que leía -afirma el autor- me sentía 
más inconforme con lo que, en esos tiempos, se estilaba escribir en mi patria" (2003: 141). No obstante, el rechazo más abierto fue hacia la denominada narrativa de la violencia que, luego del asesinato del caudillo liberal Jorge Eliécer Gaitán, privilegiaba la denuncia política en detrimento de los valores puramente estéticos.

En Colombia, como ya lo insinué, nos hallábamos entregados a un realismo sin perfiles, sujeto al tema reiterativo de la violencia. Por aquellos años, antropólogos y sociólogos habían revelado los horrores de esa barbarie durante los períodos gubernamentales de Ospina Pérez, de Laureano Gómez y de Roberto Urdaneta Arbeláez. Ahora, se sabía de los juegos de pelota con la cabeza destroncada de liberales, de los espeluznantes "cortes de franela", de la práctica de hacer engullir su corbata a quien la usara roja (...), de la costumbre de amputar el miembro viril a dirigentes liberales y plantarlo en la boca del cadáver a modo de cigarro y de otras lindezas que han colocado a nuestro país muy por encima, en términos de crueldad, de la Alemania de Hitler. La idea era, pues, que nuestra narrativa debía ocuparse de estos asuntos con exclusión de cualesquiera otros, lo cual empezaba a hacerla monotemática y tediosa (173).

De este modo, frente a la novela de la violencia partidista Germán Espinosa opta audazmente por la literatura fantástica. De esta transgresión a lo "literaturizable" de la época, surgirían sus primeros cuentos recogidos en el libro La noche de la trapa (1965), en donde echa mano de la ciencia ficción, la manipulación biológico-genética, el mito de la Atlántida, el arca de la alianza y el tiempo cíclico, entre otras opciones. En lo sucesivo, esa actitud transgresora sería la constante frente a la tradición literaria colombiana. Al punto de exclamar que "a mí lo que los novelistas colombianos hayan hecho, hagan o vayan a hacer me tiene sin cuidado. No soy, en puridad, un escritor colombiano, sino ante todo caribeño y, por tanto, universal" (Espinosa Torres, 2000: 42). Así, al localismo panfletario, Germán Espinosa opondría un cosmopolitismo sin reservas; a las premuras del presente, la poética de la historia; a la resonancia testimonial, el predominio de la estética. Actitud que, a no dudarlo, habría de resultar en extremo insolente, escapista y sin duda reaccionaria para ciertos sectores dominantes del campo literario colombiano, rabiosamente comprometidos con el realismo. No hay que olvidar que ni siquiera el enorme prestigio internacional de un escritor de izquierda como García Márquez lo libró de tener alguna vez que dar explicaciones sobre los compromisos revolucionarios del escritor de ficciones.

Por otra parte, y de manera por demás paradójica, Germán Espinosa es también uno de los más representativos continuadores de la tradición

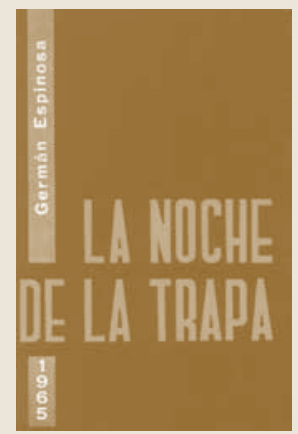

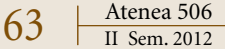




\section{LOS CORTEJOS} DEL DIABLO

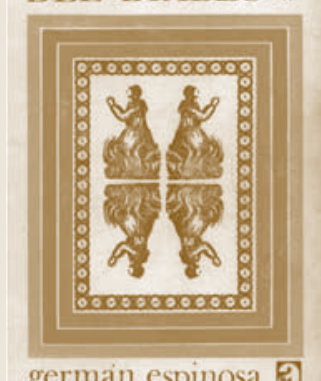

germain espinosa literaria colombiana. Prueba de ello la constituye por ejemplo su declarada admiración por los aportes ensayísticos de Baldomero Sanín Cano, por el vigor narrativo de Tomás Carrasquilla y de José Eustasio Rivera, por la herencia poética de José Asunción Silva y de Luis Carlos López, por la riqueza verbal de León de Greiff y, sobre todo, del repudiado ángel caído del modernismo colombiano: el bardo payanés Guillermo Valencia, de quien incluso fue uno de sus biógrafos más esclarecidos. "Por mi parte -confiesa Espinosa- no creo que en las artes haya que asesinar a los predecesores. La larga memoria de aquello que nos antecedió es afortunada también en las letras. Matar a Borges equivaldría a matar a Cervantes o a Quevedo" (250).

$\mathrm{Ni}$ ruptura insuperable ni acatamiento pasivo: resulta más coherente, sin duda, ver en Germán Espinosa a un autor que, gracias a una serie de disposiciones y coyunturas, logró enriquecer la tradición literaria nacional a partir de una multiplicidad de tradiciones extranjeras. De cualquier forma, la hibridación de las tradiciones es no solo un fenómeno natural, sino necesario en la dinámica de los campos de producción cultural. Más aún, cuando la conciencia de ese pluralismo refrescante se consigue a pesar del recio "modelo de nuestros propios estereotipos culturales, producidos por la vida misma y la educación misma dentro de los límites de un solo modelo nacional" (Lissa, 1986: 241).

Ahora bien, en términos generales los estudios sobre la obra del escritor cartagenero Germán Espinosa han privilegiado sus novelas históricas, especialmente, Los cortejos del diablo (1970) y La tejedora de coronas (1982). No obstante, Espinosa está lejos de ser simplemente un autor de novelas históricas. Como pocos, Espinosa sabe que toda reflexión sobre el pasado, así sea el más remoto, no constituye cosa distinta que un intento laborioso por comprender la oscura maraña del presente. El pasado, por así decirlo, es apenas un artilugio del que se vale el escritor de ficciones históricas para intentar develar el rostro huidizo de su contemporaneidad. Porque, según sus propias palabras, "a cualquier lector, hablándole del pasado, es más fácil desmontarle sus prevenciones y transmitirle lo que deseamos acerca del presente" (Espinosa, 2002: 59).

Cierto público no comprende, según he logrado vislumbrarlo, el porqué un escritor se separa de su tiempo para explorar en épocas distantes: ignora que es más fácil criticar, ironizar, satirizar lo actual remitiendo al lector a tiempos lejanos, para así desmontar su guardia. Ignora, además, las ventajas que puede aportar, cuando se trata de reflexionar sobre el destino humano, la perspectiva histórica (2002: 65). 
En la obra de Germán Espinosa, sin que importe mucho la extensión, el género, o el retroceso del reloj, existe una búsqueda común, una pesquisa inquisitiva acerca de ese conjunto de causas y efectos de las que ha surgido, no sin una buena dosis de vanidad, el hombre moderno. La cuestión de fondo, con frecuencia se olvida, no es si Espinosa ubica la peripecia de sus creaciones en los orígenes del Cristianismo, en la Cartagena de la Inquisición y los asedios piráticos, en la Europa del Iluminismo, en las guerras independentistas latinoamericanas, en la Bogotá brumosa del siglo XIX o en el Palenque épico de un monarca cimarrón. La mole que sustenta el recurso al pasado es, sin la menor duda, una legítima preocupación por el presente.

La historia funciona como un marco propicio que facilita la reflexión acerca de cuestiones políticas, ideológicas y sociales. Es el albergue de la inferencia y de la experiencia; del cuestionamiento del discurso institucional. El discurso de la historia nutre la obra de Espinosa al funcionar como instrumento para la indagación y la comprensión de los complejos procesos de mestizaje e hibridación cultural operados en América Latina. Y esa posición es una apuesta hacia el futuro, es una actitud progresista. Pensar que el autor cartagenero es un "nostálgico del pasado", alguien que piensa, de manera un tanto ingenua, que "todo tiempo pasado fue mejor" es simplemente no comprender su obra, no comprender su proyecto.

Creer que toda preocupación por el pasado es una preocupación por la muerte, es no entender el tiempo. (...) El tiempo pasado contiene nuestras semillas, nuestras raíces, el esplendor de nuestros troncos, lo más vital que poseemos para vivirnos en el presente. En él está lo que realmente somos, brotado de lo que fuimos. En él está nuestra cara, en él nació la materia de los ojos con que miramos en el espejo nuestra cara (2002: 69).

El objetivo de Germán Espinosa, visto de esta forma, se traduce en una revisión decidida del discurso histórico, entreverado de protuberantes omisiones y mentiras oficiales, a partir de una escritura que se vale de la imaginación para reconstruir, actualizar y reinterpretar el pasado. La obra de Espinosa se esfuerza por focalizar lo que la historia no ha sabido ver, por narrar lo que su discurso heterónomo no ha podido o no ha querido contar. En este sentido, no cabe duda que la ficción histórica "ha funcionado en América Latina como una eficaz hermenéutica del pasado que ha permitido al mismo tiempo una más honda comprensión de los avatares del presente continental" (Araújo, 2006: 218).

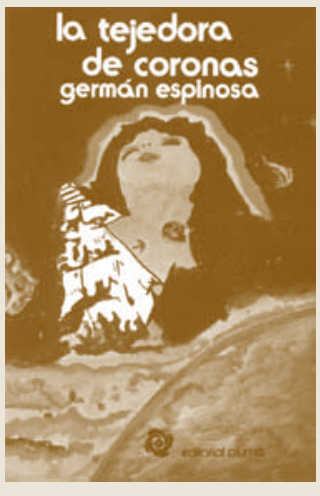


Como sostiene con acierto uno de sus críticos más acuciosos, el proyecto estético de Germán Espinosa propone una profunda reflexión sobre el concepto de nación a partir de la idea de una identidad mestiza. Idea que, por supuesto, transgrede los límites tradicionales de la nación y vincula estrechamente los discursos de la ficción, de la historia y de la religión. Pero, sobre todo, plantea "la revisión misma de la historia que se mira al espejo como mestizaje, forma de aprehensión posible de esa 'substancia' de pasado que 'gravita' sobre el presente como anacronía y levitación" (Forero, 2006: 398).

Con toda claridad, la obra de Espinosa confronta desde diferentes momentos el discurso oficial de la historia, relativizándola, cuestionándola, desmintiéndola. Recurriendo a la parodia, a la ironía, a la desacralización para construir:

Un universo textual donde la escritura no se limita a reproducir significados, sino y sobre todo, a multiplicar sentidos. A través de él es posible problematizar estructuras mentales heredadas, confiar en la imaginación como forma de conocimiento, elaborar una conciencia estética capaz de propiciar afirmaciones personales y colectivas y reconstruir memorias culturales saturadas de opresiones y resistencias (Figueroa, 2008: 23).

Así, pues, en esas incursiones al pasado -que sus contradictores solían descalificar por vetustas y escapistas- hay una visión universal, cosmopolita y, como se ha mostrado, no poca crítica a las instituciones y a los hombres que han detentado el poder, que han forjado con sus decisiones, con sus actos y, en muchas ocasiones, con su fuerza el presente y el futuro de la especie. Ahí está, por supuesto, la religión con su poder milenario, con todas sus pequeñas y grandes miserias, la mezquindad y la vergonzosa ineptitud de la clase dirigente, la cuenta de cobro para la historia, para los discursos del poder, para la misma literatura o, cuando menos, para las sectas de marrulleros que se han dado a la tarea de controlarla, de amordazarla, al extremo de -como ya hicieron con el carnaval, germen primigenio de la novela- reducirla a un epítome servil de la moda, la superficialidad y los dictámenes del mercado.

Por todo lo anterior, para Germán Espinosa el escritor es quien más se aventura en la oscuridad; quien enciende la luz para intentar comprender el presente; quien echa mano del pasado para vislumbrar el devenir; quien, en últimas, con plena convicción, sostiene que vale la pena sacrificar una vida para escribir una gran obra. 
En fin, comprendí que pese a la indiferencia que hacia mi obra acusaba la patria, en otros lugares de Hispanoamérica se me apreciaba y quería.

G. E.

Néstor García Canclini, al referirse al porvenir del pasado, afirma que "el patrimonio es el lugar donde mejor sobrevive hoy la ideología de los sectores oligárquicos" (1989: 150). Si se piensa que el canon literario colombiano es una de las más refinadas manifestaciones del patrimonio nacional, no es difícil comprender que la mayoría de sus auténticos procesos de canonización obedezcan a motivos extraliterarios, ligados más a cuestiones de legitimación política, ideológica y de clase, que al valor estético de las obras. "Ese conjunto de bienes y prácticas tradicionales que nos identifican como nación o como pueblo es apreciado como un don, algo que recibimos del pasado con tal prestigio simbólico que no cabe discutirlo" (150). En otras palabras, cierto "tradicionalismo sustancialista", esto es, aquellos grupos hegemónicos en América Latina que, desde la independencia, se las han arreglado para fijar el valor de los bienes culturales. Cabe pensar que fue justamente la versión colombiana de ese "tradicionalismo sustancialista", del que habla García Canclini, uno de los factores que más postergaron el reconocimiento de la obra de Germán Espinosa en el ámbito nacional. El escritor cartagenero, no cabe duda, fue percibido por estas esferas como una suerte de adversario. No debe olvidarse que para la ideología dominante, la que se legitima e instituye a través de la ritualización cultural y la teatralización del poder,

el peor adversario no es el que no va a los museos ni entiende el arte, sino el pintor que quiere transgredir la herencia y le pone a la virgen un rostro de actriz, el intelectual que cuestiona si los próceres celebrados en las fiestas patrias realmente lo fueron, el músico especializado en el barroco que lo mezcla en sus composiciones con el jazz y el rock (1989: 180).

Pero, por supuesto, la cuestión no se agota aquí: dentro de las razones que explican el porqué Colombia tardó tanto en reconocer el valor de Germán Espinosa es posible distinguir tanto factores literarios como extraliterarios. En el contexto de las razones literarias sería ingenuo desconocer el hecho de que García Márquez ocupó el centro del campo literario colombiano a partir de 1967. Salvo por cierta reconocida influencia de realismo 


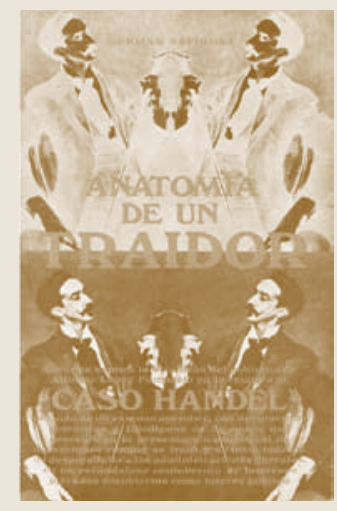

mágico en Los cortejos del diablo (1970), la actitud de Germán Espinosa eludió siempre el oportunismo fácil de quienes, en Colombia y en el continente, pretendieron sacar provecho del extraordinario éxito de Cien años de soledad. Su propuesta, enciclopédica y cosmopolita, por mucho tiempo resultó difícil de entender para el grueso del público lector.

Dentro de los factores extraliterarios, habría que mencionar inicialmente la enorme influencia de las ideologías de izquierda en los campos de producción cultural de América Latina, luego del triunfo de la Revolución Cubana. En Colombia, por ejemplo, "el acaloramiento fanático de no pocos grupos de intelectuales no se hizo esperar. Ser comunista se convirtió en una postura obligatoria si se quería brillar en el mundo de las letras y de las artes y, en los círculos esnobistas, se implantó como una moda" (2003:162). La paradoja de todo esto, aunque cueste trabajo creerlo, fue que a causa de la complejidad de su proyecto literario, por mucho tiempo la derecha, conservadora y clerical vio en Germán Espinosa a un oscuro subversivo, mientras que la izquierda, comunista y "mamerta", lo repudió abiertamente por reaccionario. Como afirma el propio autor, "lejos de buscar un término medio, los conceptos sobre mi obra o sobre mí suelen situarse en extremos antitéticos" (12).

Un factor que no debe obviarse, así genere resquemores, está constituido por sus reputados "enemigos", el más felón de los cuales, según el escritor, fue sin duda el poeta oficial Juan Gustavo Cobo Borda, insigne representante de las capillas bogotanas. Sin embargo, las zancadillas, las mezquindades, los "pactos de caballeros" y las "conjuras de silencio" de las que se queja el autor en sus memorias y en no pocas entrevistas, lo único que demuestran es la evidente ausencia en Colombia de una crítica seria y objetiva a lo largo de casi todo el siglo XX, lo cual, por desgracia, dejó el circuito literario en manos de una celosa gavilla investida con el suficiente poder para, de acuerdo con sus conveniencias y caprichos, poner y sacar de las antologías, conceder y negar premios, dominar suplementos literarios y dirigir a su arbitrio las revistas ungidas por el establecimiento. A todo lo dicho, habría que agregar la profunda animadversión que se procuró Espinosa con la publicación de Anatomía de un traidor (1973). "Libro en defensa de López Pumarejo y de López Michelsen, por razón del antiguo caso Handel, que le granjeará un veto de más de diez años en amplios sectores del país" (Espinosa Torres, 2000: 200). Para colmo de males, algunas de las figuras más respetables de la crítica literaria colombiana, tales como Ramón de Zubiría o Rafael Gutiérrez Girardot, se mostraron siempre indiferentes y jamás condescendieron a ocuparse de la obra del escritor cartagenero. 
Finalmente, es necesario resaltar que a partir del surgimiento en las principales universidades colombianas de un nuevo tipo de crítica literaria, más rigurosa, profesional y desapasionada, la obra de Germán Espinosa se ha ido paulatinamente consolidando como una de las más estudiadas en el ámbito de las letras nacionales.

\section{REFERENCIAS}

Acosta, Carmen, Figueroa, Cristo, Giraldo, Luz Mary (Eds.) (2008). Germán Espinosa. Señas del amanuense. Bogotá: Universidad Javeriana.

Araújo Fontalvo, O. (2006). "Ursúa: ficción e historia en una nueva crónica de indias". Ittaca: Revista de Lenguaje (Universidad del Cesar) 6, (216-223).

Bourdieu, Pierre (1995). Las reglas del arte. Barcelona: Anagrama.

Castillo Mier, Ariel (Ed.) (2001). Respirando el Caribe. Memorias de la Cátedra del Caribe Colombiano, Vol. I. Cartagena, Barranquilla: Observatorio del Caribe, Universidad del Atlántico.

Espinosa, Germán (2003). La verdad sea dicha. Mis memorias. Bogotá: Taurus. Espinosa Torres, Adrián (Ed.) (2000). Espinosa oral. Las 24 mejores entrevistas a Germán Espinosa. Barranquilla: Universidad del Atlántico [Recopilación de entrevistas de 1970 a 1999; breve bibliografía y biografía].

Figueroa, C. (2008). "Cartografía literaria de Germán Espinosa: rutas y trayectos de una escritura autónoma". En Acosta, Carmen, Figueroa, Cristo, Giraldo, Luz Mary (Eds.) (2008). Germán Espinosa. Señas del amanuense (Págs. 23-48). Bogotá: Universidad Javeriana.

Forero Quintero, Gustavo (2006). El mito del mestizaje en la novela histórica de Germán Espinosa. Bogotá: Universidad Externado de Colombia.

García Canclini, Néstor (1989). Culturas híbridas. Estrategias para entrar y salir de la modernidad. México: Grijalbo.

Jandová, J., Volek, E. (Ed., introd., trad.) (2000). Signo, función y valor: estética y semiótica del arte en Jan Mukarovský. Santafé de Bogotá: Universidad Nacional de Colombia, Facultad de Ciencias Humanas, Departamento de Literatura. Universidad de los Andes, Facultad de Artes y Humanidades, Departamento de Humanidades y Literatura, Plaza \& Janés Editores Colombia S. A.

Lissa, Sofía (1986). Prolegómenos a una teoría de la tradición en la música. La Habana: Criterios, pp. 221-241.

Ortega, Manuel Guillermo (2008). Conversando con Germán Espinosa. Nueva Gaceta 14.

Torres, Carlos Luis (2007). “Germán Espinosa: la escritura versal”. Fractal, 4546, abril-septiembre, año XII, volumen XII, (101-112).

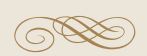

